\title{
Issues In Conducting Empirical Research In The People's Republic Of China: A Case Study Of Primary Research On Purchasing Practices In Chinese Small Businesses
}

Katharine A. Bohley Hubbard, University of Indianapolis Jeffery H. Adams, University of Houston-Downtown

Deborah D. Whitten, University of Houston-Downtown

\begin{abstract}
This paper addresses the issues involved in conducting empirical research in the People's Republic of China (PRC). Major hurdles that researchers have to overcome when conducting empirical research in the PRC, include language, cultural issues, cost of the research, obtaining local contacts, and government restrictions. The challenges faced in an actual research effort in China will be compared and contrasted to research issues discussed in the academic literature. Finally, recommendations for conducting empirical research in the PRC are presented.
\end{abstract}

Keywords: Research Methods, Purchasing, Supply Management, Small Business, SMEs, China

\section{INTRODUCTION}

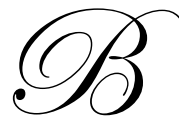

ecause of China's tremendous economic growth particularly in manufacturing, the subject of Chinese business practices has become an area of major interest by many academics and practitioners alike. China has gone from being virtually absent in international trade to the world's third-most-active trading nation, behind the U.S. and Germany and ahead of Japan." ${ }^{11}$ According to the New York Times, since 1978 China's gross domestic product has risen fourfold; in straight dollar terms, Moreover, China's economy is the world's sixth largest, with a GDP of around \$1.4 trillion. Exports have grown by an average of $27.7 \%$ and foreign direct investment has grown by an average of $30 \%$ per year since $1985 .^{2}$

Despite an abundance of literature about the overall economic growth in China, a limited amount of primary research has been conducted in the PRC. There is considerable secondary information available in China but it is often old, questionable, or inaccurate. According to Oliver and Coulter (2004), China's markets are difficult to research and understand because of five factors. First, the country's size, comparable only to the Untied States, India, Brazil, and the European Union. Second, is its rate of market change, which compares only to Brazil and India. Fourth, the Chinese businesses are small, regional companies and the industries are fragmented and diverse. Fifth and finally, individuals and businesses are often unreceptive to direct research inquires. (Oliver and Coulter, 2004).

This paper will address the issues involved in conducting empirical research in the People's Republic of China (PRC). The challenges faced in an actual research effort in China will be compared and contrasted to research issues discussed in the academic literature. Finally, recommendations for conducting empirical research in the PRC are presented.

\footnotetext{
${ }^{1}$ Fishman, T.C. "The Chinese Century" New York Times Magazine. July 4, 2004.

${ }^{2}$ Dernberger, R.F. (1999) The People's Republic of China At 50: The Economy, The China Quarterly, 159: 607-615.
} 


\section{CHINESE CULTURAL ISSUES}

In contrast to the U.S. population, which is mostly urban, two-thirds of the Chinese people still live in rural areas, laboring primarily in rice or wheat cultivation. Traditional Chinese agriculture is peasant farming. Before the 1980s, agrarian values trumped business values. When during the Cultural Revolution Mao Tse-tung sent bureaucrats and students to be "reeducated" by the peasantry, he was reflecting the deep-seated belief in the virtues of rural life. Indeed, Chinese philosopher Fung Yu-lan explains in his writings that Chinese sages historically distinguished between the "root" (agriculture) and the "branch" (commerce). Social and economic theories and policies tended to favor the root and slight the branch, thus, those individuals, merchants, were looked down upon.

The writings of Confucius served as the foundation of Chinese education for some 2,000 years. Confucius maintained that a society organized under a benevolent moral code would be prosperous and politically stable and therefore safe from attack. He also taught reverence for scholarship and kinship. Confucius defined five cardinal relationships: between ruler and ruled, husband and wife, parents and children, older and younger brothers, and friend and friend. Except for the last, all the relationships were strictly hierarchical. According to the Confucius belief, rigorous adherence to these hierarchical relationships yielded social harmony, the antidote for the violence and civil war of Confucius's time.

Roughly contemporary with Confucius was Lao Tsu, the inspiration for Taoism, whose fundamental notions involve the relationship of yin (the feminine, dark, and passive force) to yang (the masculine, light, and active force). The two forces oppose and complement one another simultaneously. They cannot be separated but must be considered as a whole. The implications of the collision and collusion of yin and yang are pervasive, affecting every aspect of life from traditional medicine to economic cycles. According to Lao Tsu, the key to life was to find the Tao--"the way" between the two forces, the middle ground, and a compromise.

Both Lao Tsu and Confucius were less concerned about finding the truth and more concerned about finding the way. These moral values express themselves in the Chinese the management styles and impacts market research. Chinese managers seem to be more concerned with the process more than the goal, thus the best research results are derived only through a long process.

Guanxi is often referred to personal connections; however, it is a challenging concept for Americans to grasp. Americans do put a premium on building relationships via networking, information, and institutions, the Chinese place a premium on building relationships on the social capital of an individual within group of friends, relatives, and close associates. Moreover, Good guanxi also depends on a strict system of reciprocity, or what the Chinese call hui bao, which is not immediate like the Americans expect. (Graham and Lam, 2003) Because of increased interactions with westerners with China the importance of guanxi has been reduced, however, it is still an important social force. More often than not, the person with the best guanxi is able to make the connection one needs to conduct market research in China. Even though, it is imperative to use guanxi when conducting research in China, it is not a substitute for systematic research.

If westerners want to conduct primary research in China, they do not have much hope without the zhongjian ren, the intermediary. A talented Chinese go-between is indispensable even after the initial meeting takes place. In China, trust must be transmitted via guanxi, a trusted business associate, must pass you along to his trusted business associates. This is crucial when it comes to conducting empirical research in China.

\section{COMMUNICATION ISSUES IN CHINA}

For face-to-face meetings and case studies someone who is very familiar with the local dialect is required. Only someone who is very familiar with the language and culture can read and explain the moods, intonations, facial expressions, and body language. Frequently, only the intermediary (zhongjian ren) can translate the actual meaning. More specifically, "when an impatient Westerner asks what the Chinese think of a proposal, the respondents will invariably offer to kan kan or yanjiu yanjiu, which means, "Let us take a look," or "Let us study it"--even if they think the proposal stinks. This is where the zhongjian ren can step in because he is an interpreter not so much of 
words as of cultures. Often, the two parties can say frankly to the intermediary what they cannot say to each other."

Rather than answer questions, the Chinese are more likely to change the subject, turn silent, ask another question, or respond by using ambiguous and vaguely positive expressions with subtle negative implications, such as hai bu cuo ("seems not wrong"), hai hao ("seems fairly all right"), and hai xing or hai ke yi ("appears fairly passable").

Adler, Campbell, and Laurent (1989) state that the descriptions given by Chinese managers about their organizations in many cases did not match with the preliminary results. They write that when the managers were asked about the gap between descriptions and results they indicated "that they responded the way they wanted China to be, not the way China actually is; that they had described an ideal picture."

\section{PRIMARY RESEARCH ISSUES IN CHINA}

There are numerous reasons why primary research in China is challenging. First, the market research industry has operated in China for only a decade. Also, secondary data cannot be trusted in China. Due to the level of economic development, similar to Brazil and India, creates an ever-changing environment, which creates challenges for conducting research, partially due to the lack of trust of researchers and the fragmented markets in this area of the world, which is compounded by the size of China.

Both Business-to-Business (B2B) and Business and Consumer (B2C) market research are relatively new to China. The logistics of B2B market research in China is more challenging than B2C. It takes several attempts to get a meeting with most organizations in China. The most common type of B2B research in China is anecdotal research, use of experts, use connections or relationships (guanxi), secondary sources, and systemic primary.

Anecdotal research is common in China. It occurs when a researcher questions consumers, suppliers, or friends. One should use anecdotal research to brainstorm and prepare for further research. One must determine if the information offered is true and who else had been privy to this information.

Experts from China's government, academic institutions, industry associations are helpful in providing insight on market trends, regulations, and offering suggestions for approaches on specific projects. Since these experts have the gained the respect of others over time, they are more likely to be able to create a relationship in which research can be fostered. On the other hand, these types of experts in China, tend to be more out of touch with the latest trends, than this group in a developed country, thus one should not solely rely on this type of expert in China.

Secondary research is always a possibility when conducting research in China. There are overlaps in the data, since the Chinese government is vertically organized, each industry's ministry collects it own data. If one is to use secondary data collected in China, it is impetrate to compare multiple courses over a long period.

According to Oliver and Coulter (2004), primary research is the most extensive, reliable, useful, time consuming, and costly approach to research in China, which is true in the rest of the world. Oliver and Coulter further state that cultural differences are the main reason for differences in answers and in the interpretations of responses. Similar to Oliver and Coutler (2004), the authors found the company representative are less likely to speak negatively of their organizations and less likely to speak positively of their competitors than Westerners. The main reason for the difference between the Westerners and Chinese in the range negativity or positive comments made is due to Mianzi. Mianzi defines a person's place in his social network; it is the most important measure of social worth. (Graham and Lam, 2003) Sources of face can be wealth, intelligence, attractiveness, skills, position, and, of course, good guanxi. However, while Americans tend to think in absolute terms--a person either has prestige and dignity or does not--the Chinese think of face in quantitative terms. Face, like money, can be earned, lost, given, or taken away. (Graham and Lam, 2003) 
Adler, Campbell, and Laurent (1988) noticed that responses by Chinese subjects to Likert questions tend to be bimodal. Culpepper, Zhao, \& Lowery (2002) also discuss the tendency for extreme responses on Likert scales in Chinese surveys. They state that Likert type questions are susceptible to culture related response bias, which is a major problem because the primary measurement tool used in survey research is the Likert scale. They note that one theory for this tendency is that Chinese culture is less adversarial than western cultures and that debate between opposing viewpoints is seen as undesirable due to historical Confucian influence. Chinese decision makers often tend to revert to time-tested and widely accepted ideas rather than weigh the benefits of opposing arguments.

As a result of these cultural issues, the use of traditional survey research methods in China can be problematic. Great care must be taken in research design in order to insure that cultural issues are taken into account. The initial research efforts of this study provided evidence to support the tendency for bimodal distributions to Likert scale questions. In a preliminary pretest of our purchasing survey with a small group of Chinese managers a preponderance of extreme answers, both high and low, was noticed.

According to Oliver and Coutler (2004), it is imperative for the interviewer to have first-hand experience with primary research, ask questions in which the respondent must provide a concrete answer, and crosscheck the responses as much as possible.

Adler, Campbell, and Laurent (1989) conclude that from their results they learned more about the transferability of western-based concepts to China than they learned about the People's Republic of China itself. As such they state that the results of their research should be treated as tentative at best and should be used as an "opportunity to learn about the process of cross-cultural research rather than the specifics of the Chinese managerial style." They further state "observations and interpretations may, in fact, be too culture-bound to significantly advance our understanding. Whereas this research study was originally designed to advance our understandings of Chinese managerial behavior, it in fact lead us to new understandings of the ways in which we must question the research process itself."

\section{RESEARCH STUDY}

The primary purpose of this research is to investigate the purchasing practices within small and medium sized manufacturers in the PRC. Due to cultural issues with Likert scale instruments the researchers opted for a multiple case methodology, to gather data for this study. Taking into consideration of the various types of information usefulness as reported by According to Oliver and Coutler, the research created a study that would use all types of information collection for this study. Nor example, anecdotal research and guanxi were utilized with the assistance of the translator.

The first phase of this research project involved on-site visits to six manufacturers in Ningbo City in March 2005. Ningbo City, which has a population of over one million, is a three-hour drive from Shanghai and is located in the Zhejiang province in Southeastern China. The Ningbo Economic and Technological Development Zone was established in 1984. Ningbo is a good area in which to perform a empirical study of Chinese businesses, because of the large variety of manufacturers and businesses in the Ningbo region and because of contacts at the Ningbo Institute of Technology (NIT), Zhejiang University.

\section{RESEARCH CHALLENGES EXPERIENCED}

Major issues that had to be overcome in order to accomplish this study included language, cultural issues, cost of the research, local contacts, and government regulation. Language and local contacts were perhaps the two largest hurdles in performing research in the PRC. A former graduate student now living in Ningbo was hired to work on this study who was knowledgeable about regional dialect and customs.. The local contact was essential in that they were able to make contact with companies, arrange interviews, and serve as a translator during site visits. Other help was received from a Professor at the University of Indianapolis who has extensive contacts in the PRC. Without the help of these two individuals this research project would have been impossible. Local contacts at the Ningbo Institute of Technology, Zhejiang University (NIT) were also essential in performing this research. 
In order to make site visits to local businesses the President and the Dean of the School of Business at NIT had to use their influence. In addition, government officials, similar to our Department of Commerce, needed to be involved. NIT administrators and government officials reviewed the research project and granted approval before it was allowed to proceed. The researchers with the assistance of NIT were able to gain approval from local government agencies, Ningbo Yinzhou Science and Technology Bureau, Ningbo Yinzhou Industrial and Commercial Bureau, and the Ningbo municipal government. Also the involvement of NIT, added local legitimacy to the research project, which helped in gaining access to companies. Another major hurdle of performing research in the PRC is cost. For instance the cost of travel alone can be several thousand dollars. One way to reduce costs is to combine research travel with trips the faculty has scheduled to teach at NIT.

Local contacts with this project indicated that businesses in general distrust nongovernmental research projects particularly surveys. The Chinese did indicate that government sponsored research has a higher degree of trust and participation by businesses. Also, businesses often do not see the benefit in participating in research projects. As a result, businesses are often not cooperative in providing any information about themselves. Part of the distrust is the result of a credit crisis that has caused many businesses to be hesitant about sharing information concerning their organizations. Small businesses in China are very concerned about disclosing information about their purchasing operation and supplier base in a highly competitive environment.

On the site visits a government official and/or a top administrator accompanied the researchers. In all of the meetings the President/CEO was present along with the representatives of purchasing. It was obvious that in many if not all cases that the President/CEO wanted to insure that their employees gave what they perceived as the right answer to the questions.

\section{RECOMMENDATIONS}

The researchers strongly urge others to consider cultural issues conducting research in the PRC. The first specific recommendation is to establish relationships with native Chinese who can assist in the research effort. A native of the region to be studied can use guanxi to make the contacts in order for the research to have more of an inside approach. Another recommendation is to have a local academic institution or governmental agency partner with or sponsor the research. Respondents are more likely to be trusting and divulge more information when in an interview when someone from the local area is involved. The third recommendation is to consider cultural issues in developing a method of data gathering. Surveys can be problematic due to low response rates and the bimodal issues described by Adler, Campbell, and Laurent (1988). Case studies can be an excellent method for conducting research in the PRC but researchers need to keep in mind that external validity issues need to be taken into account. For example, the companies visited are often the organizations that local contacts want the researchers to visit; thus a distorted view of the state of organizations in the PRC could be an issue. Moreover by focusing on one city or region might not be culturally representative of the rest of China. Regardless of the method of collecting data in China, research results in the PRC should be carefully studied in regards to validity issues. More research is needed to determine what method or methods of research would be best to ensure that external validity is not compromised.

\section{CONCLUSIONS}

In closing, the hurdles for conducting research in the PRC are formidable, but the benefits can be large. By default, the level of economic development creates challenges for conducting research, because the industries tend to fragmented and business are constantly changing, which is only compounded by the massive size of China. In addition to taking the types of research into consideration, one must consider the cultural issues when conducting research in China. An important point to consider is due to the size, diversity, and constantly changing nature of Chinese society it is very important for more empirical research to be performed in the PRC. The fast changing nature of Chinese society means that past research findings even though they be only a couple years old may be no longer relevant. 


\section{REFERENCES}

1. Adler, N.J., Campbell, N.,\& A. Laurent. 1989. In search of appropriate methodology: From outside the People's Republic of China Looking in. Journal of International Business Studies, 20: 61-74.

2. Culpepper, R.A., Zhao, L.,\& C. Lowery. 2002. Survey Response Bias Among Chinese Managers. Academy of Management Proceedings. IM:J1-J6.

3. Dernberger, R.F. 1999. The People's Republic At 50: The Economy, The China Quarterly, 159: 607-615.

4. $\quad$ Fishman, T.C. The Chinese Century. New York Times Magazine, July 4, 2004.

5. Graham, J. and M. Lam. 2003. The Chinese Negotiation, Harvard Business Review, Vol. 81, Issue 10: 8291.

6. Mentzer, J.T., and D. Flint. 1997. Validity In Logistics Research. Journal of Business Logistics, Vol. 18, No. 1: 199-215.

7. Oliver, C., and J. Coulter, 2004. China Market Research Strategies, China Business Review, Vol. 31, Issue 3: 54-59. 